\title{
Anxiety and depressive symptoms during pregnancy, perceived control and posttraumatic stress symptoms after childbirth: A longitudinal mediation analysis
}

Journal of Health Psychology I-II

(C) The Author(s) 2018

Reprints and permissions: sagepub.co.uk/journalsPermissions.nav DOI: 10.1।77/1359105318787018

journals.sagepub.com/home/hpq

@SAGE

\author{
Tânia Brandão',2 (i), Rute Brites', Odete Nunes', \\ Mónica Pires' and João Hipólito'
}

\begin{abstract}
This longitudinal study evaluated the mediating role of sense of control during labour in the association between anxiety and depression levels during pregnancy and postpartum posttraumatic stress disorder symptoms. Participants were 57 women. Anxiety and depression were assessed during pregnancy; sense of control and childbirth-related posttraumatic stress disorder symptoms were collected 6-8 weeks after childbirth. Higher levels of anxiety and depression were associated with more postpartum posttraumatic stress disorder symptoms through lack of perceived control. For depression, this happened only for primiparous. Interventions targeting mechanisms enhancing perceptions/feelings of control should be offered to these women to prevent/minimize childbirth-related posttraumatic stress disorder.
\end{abstract}

\section{Keywords}

anxiety, childbirth-related posttraumatic stress, depression, labour perceived control, longitudinal study, perceived control, pregnancy, trauma

\section{Introduction}

The experience of giving birth is an important time in any woman's life. However, it is a highly individual experience and can lead to positive or negative psychological effects, depending on a series of factors (e.g. Smarandache et al., 2016; Waldenström et al., 2004). Exploring negative psychological effects resulting from childbirth is paramount since they can impact not only the well-being of the mother but also the well-being of the child and the development of a healthy mother-infant relationship (Ayers et al., 2016; Parfitt et al., 2014; Rauch et al., 2013; Waldenström et al., 2004).
In the late 20th century, the delivery event was recognized as a potential stress agent that may trigger posttraumatic stress disorder (PTSD) symptoms (Alder et al., 2006; Cohen

\footnotetext{
'CIP, Departamento de Psicologia, Universidade Autónoma de Lisboa Luís de Camões, Portugal ${ }^{2}$ Centro de Psicologia da Universidade do Porto, Portugal

Corresponding author:

Tânia Brandão, CIP, Departamento de Psicologia,

Universidade Autónoma de Lisboa Luís de Camões, II50023 Lisbon, Portugal.

Email: tbrandao@autonoma.pt
} 